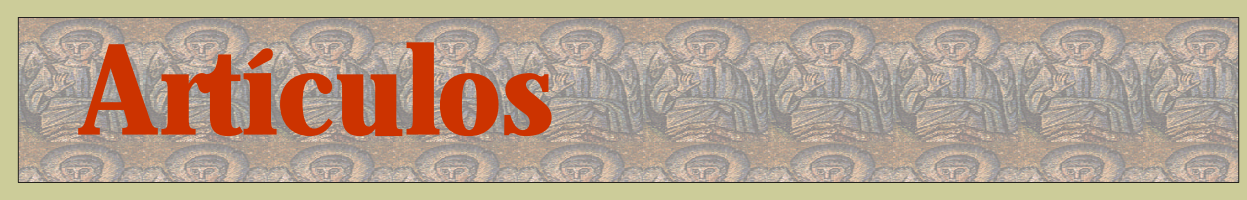

\title{
El comportamiento en la búsqueda de información de los investigadores del área de humanidades y ciencias sociales
}

\author{
Juan José Calva González \\ Centro Universitario de Investigaciones Bibliotecológicas \\ Universidad Nacional Autónoma de México \\ 04510, México, D.F., \\ E-mail: jjcg@ servidor.unam.mx
}

Trabajo recibido el

20 de noviembre de 1999

*

Trabajo

aceptado el 28

de noviembre de 1999

\section{RESUMEN}

El documento presenta una parte de una investigación mayor realizada en las comunidades cientificas del área de humanidades y ciencias sociales de la Universidad Nacional Autónoma de México, enfocada principalmente al estudio del comportamiento en la búsqueda de información de los investigadores de estas área. Lainvestigación consistió en indagar cuáles son las fuentes y recursos informativos que utilizan losinvestigadores, así como si existía alguna relación entreel tipo y etapa de investigación, y la categoría de los investigadores con el tipo de fuente y recurso informativo que utilizan cuando tienen necesidades de información. Se utilizó la técnica de la encuesta utilizando un cuestionario aplicado auna muestra estratificada, lo anterior debido a la dispersión geográfica y la heterogeneidad del número de investigadores adscritos a cada Centro e Instituto del Subsistema de Investigación en Humanidades de la UNAM. Los resultados obtenidos de la aplicación del instrumento se analizaron de forma descriptiva y utilizando algunas pruebas estadísticas para comprobar si existe alguna relación entre los elementos mencionados anteriormente. Los resultados fueron cotejados con estudios similares realizados en el extranjero y concuerdan en algunos aspectos como son los siguientes: utilizan principalmente las monografías antes quela publicaciones periódicas, asimismo usan las bibliotecas como recurso principal y posteriormente el contacto con colegas. Además se encontró la existencia de una asociación entre la categoría que ocupan los investigadores y el uso de las fuentes y recursos informativos.

Palabras clave: Comportamiento informativo, Recursos de información, Necesidades de información. 


\section{INVESTIGATIVE BEHAVIORS OF RESEARCHERS IN THE FIELDSOF HUMANITIESAND SOCIOLOGY \\ JuAN José CALVA-GonZÁLeZ}

ABST RACT

The article represents part of a larger research endeavor that focuses on the research search behaviors of scientists within the humanities and social sciences community of the Universidad Nacional Autónoma de México (UNAM-The Mexican National Autonomous University). The research project attempts to quantify the sources and information resources used by researches and in turn examine whether patterns exist between these and the type of research project, the researcher's field and the stage at which the projects are advanced. A survey instrument was designed and applied to a stratified sample, owing to the geographic dispersion and heterogeneity of the universe of researchers attached to each Center and Institute of the Research Sub-System in Humanities of the UNAM. The results obtained were analyzed descriptively and through the application of several statistical packages. The results were then compared to those of similar studies carried out in foreign countries, which yielded certain parallels in the researchers' behaviors, most notably their use of monographs before periodical publications and their use of libraries as a main source and later collegial contacts. An association between the researcher'sfield and sources and information resources used was also identified.

Key Words: Informational Behavior, Information Resources, Information Needs.

\section{INTRODUCCIÓN}

El presente documento es una pequeña parte de una investigación más amplia realizada en las comunidades científicas de la Universidad Nacional Autónoma de Méxi$\mathrm{CO}^{1}$ (UNAM) y sólo presenta lo relativo al comportamiento en la búsqueda deinformación de los investigadores del Subsistema de Investigación en Humanidades. Conocer el comportamiento informativo de la comunidad científica a la cual debe atender una biblioteca o unidad de información, repercute en el desarrollo de colecciones, diseño de los servicios y herramientas que sirven para satisfacer las necesidades de información de sus usuarios, y también para cumplircon lafinalidad depreservar, organizary difundirlainformación sin importar el material en que ésta se encuentre registrada. ${ }^{2}$

También en otros países se han efectuado estudios sobre el comportamiento informativo de diversos grupos o sectores de la sociedad. Así, existen trabajos sobre:

$$
\begin{aligned}
& \text { mujeres } \\
& \text { débiles mentales } \\
& \text { negros }
\end{aligned}
$$

1 El título de la investigación es: Las necesidades de información de los investigadores del área de humanidades y ciencias sociales, y del área científica de la UNAM

2 Estela Morales Campos, "Bibliotecología e información" - En: BdetindelaAsøiaciónAndaluzade Biblictecarios - Año, 5, no. 15, 1989. - p. 13-21. 
El comportamiento en la búsqueda de información de los investigadores del... 13

* ancianos

* estudiantes de diversas carreras, áreas y nivelescomunidades académicas de diferentes instituciones y países profesionales de áreas específicas:

* sociólogos

* economistas

* historiadores

* médicos

* químicos, etcétera

* empresas de determinados ramos:

* negocios

* consultorías

* metalúrgicas, etcétera

Algunos estudios se han realizado en diferentes medios (p.e. rural - urbano) y existen muchos otros más.

Pero hay pocos estudios que se refieren a investigadores, y sobre todo a los del área de humanidades y de ciencias sociales. Entre los autores que han estudiado el sector de humanidades (aunque no precisamente a los investigadores) tenemos entre otros a Corkill (1978), Stone (1980), D ay (1985), Fulton (1991), Case (1991) y Stieg (1981).

Para el área de ciencias sociales (aunque no precisamente se enfoque sobre los investigadores) podemos citar a Kumar (1984), Feliciano (1984), Agrawal (1987), Heim (1987) y Slater (1988), (1989).

Algunos de los resultados de los estudios realizados por estos autores fueron utilizados para la investigación desarrollada en las comunidades científicas del Subsistema de Investigación en Humanidades de la UNAM.

Estas son algunas predilecciones de los investigadores de humanidades y ciencias sociales cuando están a la búsqueda de información:

* prefieren el uso de la biblioteca sobre otros recursos como el contacto con colegas;

* para estas comunidades no es predominante recurrir a colegas; recurren más al uso de libros (o monografías) que a revistas (o publicaciones periódicas);

* privilegian el uso defuentes referenciales (bibliografías, índices y abstracts).

- ciertos sectores de estas comunidades utilizan fuentes de datos numéricos (estadísticas, censos, etc.) y también de otros tipos: edificios, pinturas, etcétera.

Los diversos estudios realizados por los autores citados utilizan diferentes métodos y técnicas para el desarrollo de sus trabajos, los cuales van desde la encuesta y la aplicación de un cuestionario hastala utilización de la entrevista con diferentes modalidades: estructurada, semiestructuraday totalmente abierta. Algunos estudios utilizan 
un riguroso muestreo de los sujetos a encuestar y otros emplean pequeñas muestras no representativas que sólo dan una idea de lo que ocurre.

Laindagación con los investigadores del área de humanidades y ciencias sociales de la Universidad Nacional Autónoma de México, se inició a partir del supuesto de que ellos, como cualquier persona o sector de la sociedad, presentan un cierto comportamiento informativo al buscar la información que necesitan y que éste se relaciona con su actividad laboral, que consiste en investigar.

La escasez de investigaciones nacionales acerca del comportamiento informativo sobre todo los investigadores, hizo que esta investigación partiera de las siguientes interrogaciones:

¿Cuál es el comportamiento informativo de los investigadores al buscar información? ¿Cuál es el recurso informativo al que acuden principalmente? ¿Cuál es la fuente de información que utilizan principalmente? ¿Existe una relación o asociación entre el tipo de investigación, la etapa de investigación, la categoría que ocupan los investigadores y la utilización de fuentes y recursos informativos?.

La investigación tuvo los siguientes objetivos:

a) Determinar el comportamiento informativo de los investigadores cuando éstos buscan información.

b) Identificar el recurso informativo que utilizan con mayor frecuencia.

c) Identificar la fuente de información que utilizan con mayor frecuencia.

d) Determinar la existencia de alguna asociación o relación entre el tipo de investigación, la etapa de investigación, la categoría de los investigadores y la utilización de fuentes y recursos informativos que tienen los investigadores de humanidades y ciencias sociales cuando necesitan información.

Tomando en consideración que estos investigadores, presentan un comportamiento informativo durante su búsqueda de información y para cumplir con los fines de la presente investigación, se plantearon las siguientes hipótesis:

Los investigadores requieren principalmente de las bibliotecas, y después de otros recursos, como es el recurrir a los colegas.

Los investigadores utilizan las monografías como principal fuente de información y en segundo lugar las publicaciones periódicas.

Existe una asociación o relación entre el tipo de investigación, la etapa de investigación yla categoría que tienen los investigadores, y el uso de las fuentes y recursos informativos.

El estudio consideró como recursos los siguientes elementos:

* los colegas,

* las bibliotecas, hemerotecas, centros de documentación, archivos, etcétera,

* la colección documental propia,

* las colecciones documentales particulares de colegas,

* la experiencia personal,

* los expertos en el área,

los congresos, conferencias, seminarios, encuentros,

* las bases de datos bibliográficas (ej. medline, psyclit) y 
* los bancos de datos especiales (ej. bancos de genes, bancos de datos numéricos, etcétera).

Las fuentes consideradas fueron las siguientes:

- las monografías (libros, tesis, documentos, etcétera),

* las publicaciones periódicas (revistas, diarios, anuarios, etcétera),

* las publicaciones oficiales (informes de organismos nacionales y extranjeros, etcétera),

- las obras de consulta (enciclopedias, diccionarios, manuales, etcétera),

* las fuentes referenciales (índices, abstracts, bibliografías, etcétera),

* los material audiovisual(casetes, videos, etcétera),

los documentos técnicos (patentes, partituras, planos, mapas, etcétera) y

- las fuentes de datos numéricos (indicadores, estadísticas, etcétera).

Las etapas de investigación se dividieron en:

* inicial,

* intermedia y

* final.

Los investigadores participantes en la investigación tenían las categorías de:

* asociado 0

* titular.

Se consideraron dos tipos de investigación:

* básica y

* aplicada.

El presente documento señala en la parte introductoria los datos generales de la investigación como antecedentes, objetivos y cuestiones planteadas. Posteriormente se describe de manera general al personal que realiza las labores deinvestigación en los Centros e Institutos de investigación pertenecientes al Subsistema de Investigación en Humanidades de la UNAM, los cuales constituyen la población que se va a estudiar. Luego se presenta un apartado que describe la metodología utilizada, cómo se obtuvo la muestra y el instrumento que se aplicó. Finalmente se presentan y analizan los resultados de la investigación antes de expresar las conclusiones y sugerencias que produjo el análisis de los resultados.

\section{LOS IN VESTIGADORES EN EL SUBSISTEMA DE INVESTIGACIÓN EN HUMANIDADES}

La Universidad Nacional Autónoma de México debe, porley, impartir educación superior para formar profesionistas, investigadores, profesores universitarios y técnicos útiles a la sociedad; organizar y realizar investigaciones y extender con la mayor amplitud posible los beneficios de la cultura. ${ }^{3}$ Igualmente, para realizar su

3 Universidad Nacional Autónoma de México. [LEGISLACIÓN] _Legjslacoón - México : UNAM, O ficina del Abogado General, 1987. - p. 11 
función docente y de investigación establecerá las facultades, escuelas, institutos y centros de extensión universitaria que juzgue convenientes. Se menciona en la Legislación que la investigación se realiza principalmente en los institutos y centros de la institución. Los institutos y centros en los que se realiza principalmente la investigación en humanidades y ciencias sociales son:4

* Instituto de Investigaciones Antropológicas

* Instituto de Investigaciones Bibliográficas, que incluye a la Biblioteca Nacional y a la Hemeroteca Nacional

- Instituto de Investigaciones Económicas

* Instituto de Investigaciones Estéticas

* Instituto de Investigaciones Filológicas

* Instituto de Investigaciones Filosóficas

* Instituto de Investigaciones Históricas

- Instituto de Investigaciones Jurídicas

- Instituto de Investigaciones Sociales

* Centro Coordinador y D ifusor de Estudios Latinoamericanos

* Centro de Estudios sobre la Universidad

* Centro de Investigaciones sobre América del Norte

- Centro de Investigaciones Interdisciplinarias en Ciencias y Humanidades

* Centro Regional de Investigaciones Multidisciplinarias de la UNAM

* Centro Universitario de Investigaciones Bibliotecológicas

En la universidad el personal académico está integrado por profesores, investigadores, ayudantes y técnicos académicos.

Los profesores e investigadores ordinarios son los que tienen a su cargo las labores permanentes de docencia e investigación, y pueden ser de medio tiempo o tiempo completo y tener la categoría de asociado o titular en cualquiera de sus tres niveles $\mathrm{A}, \mathrm{B}, \mathrm{y} \mathrm{C}$.

Parala presente investigación la población seleccionada fuela de los investigadores dela Universidad Nacional Autónoma de México, específicamente los pertenecientes al Subsistema de Investigación en Humanidades.

De acuerdo con la A genda estadística de la UNAM, ${ }^{5}$ el número total de investigadores de tiempo completo en cualquiera de sus niveles (asociado o titular) es de 1506, los cuales se encuentran distribuidos en 22 dependencias del Subsistema de la Investigación Científicay en 15 dependencias del Subsistema de Investigación en Humanidades, lo que hace un total de 563 para estaúltima coordinación. Asimismo la Legislación Universitaria en su Estatuto General artículo 11 bis, menciona que para apoyarlas labores sustantivas de

4 Ibidem p. 130-131, artículo 9, modificaciones del 13 noviembre de 1996.

5 Universidad Nacional Autonóma de México. Agenda estadística 1993. - México : UNAM. D irección G eneral de Estadística y Sistemas de Información Institucionales, 1993. - p.112-113 
la universidad, ésta contará con un sistema bibliotecario que estará estructurado conforme al Reglamento General correspondiente.

Lo anterior implica que para apoyar a los investigadores en sus actividades, los Centros e Institutos de investigación cuentan con una biblioteca por lo menos, por lo que podemos decir que según la Agenda Estadística de la UNAM el Subsistema de Investigación en humanidades cuenta con 15 bibliotecas. ${ }^{6}$ Estas unidades de información que apoyan las labores de investigación, están obligadas a conocer las necesidades de información para poder satisfacerlas, lo cual también implica saber cuál es el comportamiento de los investigadores al buscar información..

\section{METODOLOGÍA}

La presente investigación fue un estudio de carácter exploratorio-descriptivo que tuvo como finalidad principal identificar el comportamiento que despliegan los investigadores que tienen características homogéneas en cuanto a su actividad y nombramiento dentro de la UNAM, cuando buscan información.

Lo primero fue analizar los diferentes métodos y técnicas que emplearon estudios similares para determinar el comportamiento al buscar información. Se encontró que la mayoría de ellos utilizó la encuesta, ya sea a través de un cuestionario o de una entrevista con los sujetos seleccionados. Esta investigación utilizó también la encuesta para recabar la información necesaria.

Así, se diseñó un cuestionario con preguntas cerradas, ${ }^{7}$ y se determinó que fuera lo más corto posible para permitir una amplia respuesta entre los sujetos seleccionados para la muestra.

La muestra se eligió con base en la población de investigadores adscritos al Subsistema de Investigación en Humanidades de la UNAM. Se piloteó el instrumento con algunos investigadores para eliminar las posibles fallas que tenía, y luego se aplicó a la muestra seleccionada. El procedimiento seguido para aplicar el cuestionario fue mandarlo por mensajería a la Secretaría Académica de cada Instituto y Centro de investigación de la UNAM, pues se pensaba que esto garantizaría una amplia contestación.

La población incluía al número total de investigadores de tiempo completo en cualquiera de sus niveles (asociado o titular), que no estuvieran de año sabático, o comprometidos con alguna comisión, o tuvieran algún tipo de licencia. El total de las listas recibidas de cada instituto y centro de investigación ascendía a 391 investigadores con las características planteadas (véase el anexo II), los cuales estaban distribuidos en 14 dependencias del Subsistema de Investigación en Humanidades (una dependencia no envió el listado de sus investigadores). El total

$6 \quad$ Idem p. 148

7 El cuestionario presentado en el anexo I es una parte del cuestionario de la investigación más amplia y sólo presenta la parte correspondiente al análisis del comportamiento al buscar información. 
de investigadores de la UNAM que reunía las características señaladas es de 1 153, incluyendo a los del Subsistema de la Investigación Científica.

La distribución que tienen los investigadores por Centro e Instituto de investigación hizo recomendable que la muestra fuera estratificada y tomada al azar para asegurar representatividad.

Se esperaba que la encuesta diera respuestas en términos de porcentajes; es decir, que arrojara el porcentaje de personas que recurría a algún recurso o utilizaba alguna fuente de información (como parte de su comportamiento en la búsqueda de información) en cada Instituto o Centro donde se ubicaba el investigador.

El tamaño de la muestra se determinó tomando en cuenta que los investigadores estaban distribuidos entre los diferentes estratos (Centros e Institutos), que la población era menor a 10 mil sujetos y que el estudio era complejo y se basaba en una formula estadística8, la cual dio una muestra total de 223 investigadores (57\%) para el Subsistema de Investigación en Humanidades. Pero como al aplicar este tipo de instrumentos es frecuente que la respuesta de contestación sea baja, se optó por determinar un rango confiable mínimo de recepción de cuestionarios. Así, utilizando la misma fórmula con una variación en el nivel de precisión, el mínimo confiable fue de98 investigadores del Subsistema de Investigación en Humanidades. D eeste modo se tendría un rango de respuesta o recepción de cuestionarios que iría de 223 a 98 para este Subsistema, y donde el mínimo aceptable para que fuera representativo sería de 98 investigadores, cifra que representa un $25 \%$ de la población.

Como se decidió realizar una muestra estratificada dada la distribución de la población en diferentes estratos (centros einstitutos) y se quería hacer una ponderación de cada estrato ${ }^{9}$ con respecto ala población total, se empleó otraformula ${ }^{10}$ con base en la cual se obtuvo el número de sujetos para encuestar por cada estrato; es decir por cada

8 Raúl Rojas Soriano. Gúa para realizarinvestigaciones sociales - México : UNAM, 1982. - p. 177

La formula empleada fue $n=\frac{\frac{Z^{2} p}{E^{2} q}}{1+\frac{1}{N}\left(\left(\frac{Z^{2} p}{E^{2} q}\right)-1\right)}$

Para establecer el rango mínimo se considero $\mathrm{E}=10 \%$

donde:

$\mathrm{n}=$ tamaño de la muestra

$\mathrm{Z}=$ nivel de confianza. Pedimos un $95 \%$ (1.96 áreas la curva normal).

$\mathrm{E}=$ nivel de precisión: pedimos un $5 \%$ (valor del intervalo donde se encuentran los valores verdaderos).

py $q=$ variabilidad del fenómeno, se les da en este un valor máximo posible entonces .5 a cada uno.

$\mathrm{N}=1153$ (total de investigadores para ambos subsistemas; 391 para el de humanidades y 762 para el de investigación científica)

$\mathrm{n}=659$ (para ambos subsistemas; $\mathrm{n}=223$ para humanidades y $\mathrm{n}=426$ para la investigación científica)

9 Festinger, L. Losmátodos deinuestigacón enlas cienaias saciales Buenos Aires : Pidós, 1979. p. 188

10 Rojas, Opat, p. 178-179. La fórmula empleada fue: $\frac{\mathrm{Nh}}{\mathrm{N}}$ (donde $\mathrm{Nh}=$ sujetos en cada estrato y

$\mathrm{N}=$ Población) y multiplicando el resultado de $\frac{\mathrm{Nh}}{\mathrm{N}}$ por el tamaño dela muestran, para su fijación. 
centro e instituto de investigación dentro del Subsistema de Investigación en Humanidades. Pese a que un instituto (Filológicas) no envió listado, existen suficientes sujetos como para tener una representatividad en el Subsistema.

Con los listados enviados por cada Centro e Instituto y los nombres de los investigadores que cumplían con las condiciones señaladas, se procedió a enumerar a cada investigador por Instituto y Centro, y con base en el tamaño de la muestra de cada dependencia se determinó al azar el número que correspondía a cada investigador. Se indicaba así a cuales de ellos les sería aplicado el instrumento, pues se buscaba que la muestra estratificada fuera representativa de la población y que los resultados pudieran generalizarse.

\section{ANÁLISIS DE LOS RESULTADOS}

Se recibieron 123 cuestionarios, 25 más de los 98 que se esperaban como mínimo. Cabe señalar que casi todas las dependencias a las que se les hicieron llegar cuestionarios, como parte de una muestra estratificada seleccionadaal azar entre sus investigadores, los regresaron. La respuesta fue excelente pese a lo que se esperaba.

Los 123 cuestionarios que se recibieron corresponden al 31 \% de la población del Subsistema de Investigación en Humanidades (391).

Para realizar los conteos de las respuestas, los cuestionarios fueron codificados y capturados en una base de datos.

Para facilitar el análisis de los resultados obtenidos con la aplicación del instrumento, se presentan divididos en 2 partes (respuestas y cruce de variables) que se describen a continuación:

\section{A) Respuestas.}

En este apartado se muestran las respuestas obtenidas a las preguntas realizadas a través del instrumento que se diseño y aplicó a los sujetos.

El $59 \%$ de los investigadores encuestados ocupa la categoría de asociado y el $41 \%$ la de titular. (vésefigura 1).

Los investigadores se encuentran distribuidos en ambas categorías (asociado y titular) de forma casi equilibrada.

Lo anterior puede indicarque hace faltaun mayor número de investigadores con grado dedoctor que puedan ocuparla categonía de titular. Para pertenecer aésta, en cualquiera de sus niveles (A, B o C), se requiere el grado de doctor ${ }^{11}$ y otros requisitos. Se considera que para hacer investigación, el personal académico debe poseer el grado de doctor dentro de su disciplina, requisito que le permitirá contar con la formación y el desarrollo académico necesarios para realizar las labores de investigación que requiere cadaCentro e Instituto de investigación de la UNAM. Los resultados reflejan que hace falta un mayor número de titulares con grado de doctor, que se dedique a la investigación.

11 Universidad Nacional Autónoma de México. [LEG ISLACIÓN] LegjsacónEstatutodd Personal Aca démica - México : UNAM, O ficina del Abogado General, 1987. 


\begin{tabular}{|l|c|c|}
\hline \multicolumn{3}{|c|}{ CATEGORÍA QUE OCUPAR I } \\
\hline CATEGORÍA & $\begin{array}{c}\text { NÚMERO DE } \\
\text { INVESTIGADORES }\end{array}$ & $\%$ \\
\hline ASO CIADO & 73 & 59 \\
\hline TITULAR & 50 & 41 \\
\hline TOTAL & 123 & 100 \\
\hline
\end{tabular}

El $58 \%$ de los investigadores se encuentran en la fase intermedia de su investigación. (véesefigra2).Con relación a la etapa de investigación, la mitad de los investigadores se encuentra en la intermedia, lo cual posiblemente se deba a que este estudio se realizó en los últimos meses del año. También cabe señalar que las investigaciones no deben, en sentido estricto, desarrollarse necesariamente en un año (ni mucho menos entre enero y diciembre), y que algunas llevan más tiempo (2, 3, 40 incluso 5 años). Esto podría explicar que haya investigadores que se encuentran en las etapas inicial y final y cifras menores.

\begin{tabular}{|l|c|c|}
\hline \multicolumn{3}{|c|}{$\begin{array}{c}\text { Figura 2 } \\
\text { ETAPA DE INVESTIGACIÓN EN LA QUE SE ENCONTRABAN LOS } \\
\text { INVESTIGADORES AL MOMENTO DE REALIZAR EL ESTUDIO }\end{array}$} \\
\hline \multicolumn{1}{|c|}{ ETAPA } & NÚM. DE INVESTIGADORES & $\%$ \\
\hline INICIAL & 23 & 19 \\
\hline INTERMEDIA & 71 & 58 \\
\hline FINAL & 29 & 24 \\
\hline TOTAL & 123 & 100 \\
\hline
\end{tabular}

El 59\% de los investigadores se encuentra realizando investigación básica. (véasefigura3).Un poco más de la mitad de los investigadores están realizando, principalmente, investigaciones básicas más que aplicadas. Es interesante observar que los investigadores están dedicados a ambos tipos de forma casi equilibrada.

Es importante quelos Centros e Institutos deinvestigación de laUNAM estén realizando tanto investigaciones básicas como aplicadas. Lo deseable es que la investigación básica produzca conocimientos originales sobre los cuales se apoye la investigación aplicada para elaborar productos de investigación que le sean útiles a la sociedad. 
El comportamiento en la búsqueda de información de los investigadores del... 21

\begin{tabular}{|l|c|c|}
\hline \multicolumn{3}{|c|}{ TIPO DE INVESTIGACION Q } \\
LOS INVESTIGADTABAN REALIZANDO \\
\hline $\begin{array}{c}\text { TIPO DE } \\
\text { INVESTIGACIÓN }\end{array}$ & NÚM. DE INVESTIGADORES & $\%$ \\
\hline BÁSICA & 72 & 59 \\
\hline APLICADA & 51 & 41 \\
\hline TOTAL & 123 & 100 \\
\hline
\end{tabular}

Los recursos que más emplean los investigadores cuando necesitan información, comesponden en primero y segundo lugares a las bibliotecas, con 80 (65\%) y 37 respuestas (30\%), respectivamente. El tercer lugar lo ocupan los expertos en el área y la asistencia a congresos, conferencias, etcétera, con 19 respuestas cada uno en ambos casos (15\%). En cuarto, quinto y séptimo lugares está la asistencia a congresos y conferencias, con 21 (17 $\%), 12$ (10\%) y6 (5\%) respuestas, respectivamente; y en sexto lugar se encuentran los expertos, con 10 respuestas (8\%). El octavo lugar lo ocupan las bases de datos bibliográficas con 4 respuestas (3\%) y apenas en el noveno lugar figura con 2 respuestas únicamente, el recurrir a colegas y abancos de datos especiales, con 2 respuestas cadauno (2\%). En décimo lugar aparece con 1 respuesta el rubro otros recursos. (vésefigra4). En el rubro otros, con unarespuestano significativa, se incluyeron: observación; entrevistas; encuestas basadas en trabajo de campo; cartografía; colecciones de cine, vídeo y audio; INTERNET; mapotecas; WWW, NETLIB; cine y TV; colecciones de arte públicas y privadas; librerías; E-mail; trabajos de campo, y observación directa de los edificios.

En cuanto a los recursos se puede observar que lo predominante es el uso de la biblioteca en primero y segundo lugares, y que solamente hasta el 9o. lugar los investigadores señalaron el recurrir a colegas. Así, se puede observar que no existe la formación de colegios invisibles entre los académicos de humanidades y ciencias sociales, dato que concuerda con lo señalado por algunas investigaciones efectuadas en países desarrollados. Esto puede deberse al comportamiento informativo característico de los humanistas y científicos sociales, como se señaló en los primeros apartados de este documento.

Asimismo a pesar de la introducción de las nuevas tecnologías de la información y la comunicación, entre ellas el acceso a Internet, hasta el momento ésta no ocupa un lugar importante en la conducta de búsqueda de información de los investigadores. Este comportamiento, indudablemente, también está influido por el medio; es decir, las humanidades y las ciencias sociales, pues la tendencia de estos investigadores es utilizar fuentes primarias, y los lugares donde se ubican éstas como son bibliotecas y archivos, principalmente, u otros sitios. 


\begin{tabular}{|c|c|c|c|c|c|c|c|c|c|c|}
\hline \multicolumn{11}{|c|}{$\begin{array}{c}\text { Figura } 4 \\
\text { RECURSOS QUE UTILIZA EL INVESTIGADOR CUANDO NECESITA INFORMACIÓN } \\
\text { LUGAR QUE LE ASIGNAN AL RECURSO }\end{array}$} \\
\hline RECURSOS & 1 & 2 & 3 & 4 & 5 & 6 & 7 & 8 & 9 & 10 \\
\hline COLEGAS & 18 & 7 & 8 & 10 & 3 & 4 & 5 & 1 & 2 & 1 \\
\hline BIBLIOTECAS & 80 & 37 & 3 & 1 & 0 & 0 & 0 & 0 & 0 & 0 \\
\hline $\begin{array}{l}\text { COLECCIÓN } \\
\text { DOCUMENTAL PROPIA }\end{array}$ & 12 & 28 & 16 & 7 & 2 & 4 & 0 & 0 & 1 & 0 \\
\hline $\begin{array}{l}\text { COLECCIÓN } \\
\text { DOCUMENTAL } \\
\text { PARTICULAR DE COLEGAS }\end{array}$ & 1 & 9 & 8 & 5 & 2 & 1 & 3 & 0 & 0 & 0 \\
\hline EXPERIENCIA PERSONAL & 2 & 4 & 17 & 8 & 9 & 2 & 3 & 1 & 1 & 0 \\
\hline EXPERTOS EN EL ÁREA & 4 & 7 & 19 & 12 & 5 & 10 & 0 & 0 & 0 & 0 \\
\hline $\begin{array}{l}\text { CONGRESOS, } \\
\text { CONFERENCIAS, } \\
\text { SEMINARIOS, } \\
\text { ENCUENTROS, ETC. }\end{array}$ & 0 & 10 & 19 & 21 & 12 & 4 & 6 & 2 & 0 & 0 \\
\hline $\begin{array}{l}\text { BASES DE DATOS } \\
\text { BIBLIOGRÁFICAS }\end{array}$ & 4 & 10 & 6 & 6 & 6 & 5 & 0 & 4 & 0 & 0 \\
\hline $\begin{array}{l}\text { BANCOS DE DATOS } \\
\text { ESPECIALES }\end{array}$ & 2 & 3 & 9 & 7 & 7 & 5 & 0 & 1 & 2 & 0 \\
\hline OTROS & 1 & 0 & 1 & 1 & 1 & 1 & 3 & 0 & 0 & 1 \\
\hline
\end{tabular}

Las fuentes que utilizan los investigadores cuando necesitan información son: en primer lugarmonografías, con 70 respuestas (57\%); en segundo lugar están las publicaciones periódicas con 61 respuestas (50\%); en tercer lugar las publicaciones oficiales, con 39 respuestas ( $32 \%$ ); en cuarto lugar las obras de consulta, con 24 respuestas (20\%); en quinto lugar las fuentes de referencia (índices, abstracts, bibliografías, etcétera), con 20 respuestas (16\%); en sexto y séptimo lugares estáel material audiovisual, con 8 y 7 respuestas $(7 \%$ y y $6 \%$ respectivamente; en octavo lugarvienen las fuentes de datos numénicos (estadísticas, indicadores, etcé tera) con 7 respuestas (6\%), y en noveno lugar otros recursos con 3 respuestas (2\%). (verefgra5) En esterubro de otros, se mencionaron: fondo reservado, cuestionarios, informes de investigación, catálogos de museos y de colecciones particulares, obras de arte, pinturas murales mayas, archivos y colecciones documentales, preprints, edificios, censos y estadísticas vitales, archivos públicos, notarías y entrevistas. 
El comportamiento en la búsqueda de información de los investigadores del... 23

En cuanto a las fuentes que utilizan los investigadores cuando necesitan información la mayoría de ellos se inclina por las monografías y éstas son seguidas por las publicaciones periódicas.

Ciertos investigadores, principalmente los adscritos a los institutos de investigaciones sociales y económicas, señalaron utilizar fuentes numéricas, comportamiento informativo que a pesar de no estar en un lugar predominante, ciertamente existe. Indudablemente tal comportamiento está ligado, habitualmente, al área de las ciencias sociales.

Los investigadores también mencionaron las fuentes referenciales, a las que recurrieron principalmente por las bibliografías más que por los índices y abstracts, tal como apuntaban los resultados de estudios anteriores ya mencionados en este mismo documento. Aunque se observa una clara tendencia a la utilización de estas fuentes, cabría profundizar en investigaciones posteriores, cuál es el uso de estetipo de fuentes y determinar con mayor precisión la importancia y lugar que tienen para los investigadores de humanidades y ciencias sociales.

\begin{tabular}{|c|c|c|c|c|c|c|c|c|c|}
\hline \multicolumn{10}{|c|}{$\begin{array}{l}\text { Figura } 5 \\
\text { FUENTES QUE UTILIZA EL INVESTIGADOR CUANDO NECESITA INFORMACIÓN } \\
\text { LUGAR QUE LE ASIGNAN A LA FUENTE }\end{array}$} \\
\hline FUENTES & 1 & 2 & 3 & 4 & 5 & 6 & 7 & 8 & 9 \\
\hline MONOGRAFÍAS & 70 & 27 & 10 & 2 & 2 & 0 & 0 & 0 & 0 \\
\hline PUBLICACIONES PERIÓDICAS & 34 & 61 & 16 & 4 & 0 & 0 & 0 & 0 & 0 \\
\hline PUBLICACIONES OFICIALES & 6 & 17 & 39 & 14 & 4 & 0 & 1 & 0 & 0 \\
\hline OBRAS DE CONSULTA & 1 & 6 & 16 & 24 & 9 & 7 & 2 & 0 & 0 \\
\hline FUENTES REFERENCIALES & 4 & 1 & 11 & 21 & 20 & 3 & 1 & 2 & 0 \\
\hline MATERIAL AUDIOVISUAL & 1 & 0 & 3 & 4 & 1 & 8 & 7 & 1 & 1 \\
\hline DOCUMENTOSTÉCNICOS & 0 & 2 & 3 & 1 & 4 & 7 & 6 & 2 & 0 \\
\hline FUENTES DE DATOS NUMÉRICOS & 5 & 4 & 7 & 13 & 14 & 5 & 2 & 7 & 0 \\
\hline OTROS & 1 & 2 & 2 & 2 & 3 & 2 & 2 & 1 & 3 \\
\hline
\end{tabular}

Asimismo algunos investigadores señalaron utilizar otros tipos de fuentes entre las que se encuentran: fondo reservado, obras de arte, edificios, etcétera. Esto confirma los resultados expresados por otros estudios acerca de que los humanistas utilizan otros tipos de fuentes primarias dependiendo de la investigación que estén desarrollando.

Es indudable que dependiendo de la investigación que se encuentren desarrollando los investigadores del área de humanidades, éstos acudan a las fuentes 
originales como pueden ser los edificios y su arquitectura o los murales encontrados en las ruinas mayas, por especificar algunos ejemplos.

Las unidades de información deben responder al comportamiento informativo de búsqueda informativa de los investigadores en lo que se refiere a acceso a las fuentes originales, una vez que éstas son identificadas.

\section{B) Cruce de variables}

En este apartado se expone el análisis descriptivo y estadístico del cruce de variables utilizando la chi cuadrada $\left(\mathrm{X}^{2}\right)^{12}$ el coeficiente de contingencia de Pearson $(\mathrm{C})^{13}$. Con este análisis se puede encontrar si existe alguna asociación entre las variables: etapa de investigación, tipo de investigación, categoría del investigador y uso de fuentes (sólo en lo que respecta a: monografías y revistas) y recursos (sólo lo que respecta a bibliotecas y colegas).

Para este análisis y con base en lo expuesto en el apartado anterior sólo se tomaron como recursos a la bibliotecay a los colegas, y como fuentes a las monografías y publicaciones periódicas. Se buscaba comprobar que lo planteado en este estudio fuera similar a lo consignado en estudios anteriores a éste realizados en el extranjero.

Los investigadores que dijeron recurrir a colegas en primer lugar cuando necesitan información en las diferentes etapas de la investigación, sumaron 16 sujetos de 71, un $23 \%$ parala intermedia, 1 sujeto de 23, un $4 \%$, para la inicial, y sólo un sujeto de 29, un $3 \%$, para la final. (vésefigra 6). Calculando las medidas de asociación se obtuvo: $\left(\mathrm{X}^{2}\right)=8.401$ y $\mathrm{C}=.0639 .14$

No existe asociación ${ }^{15}$ entre la etapa de investigación (inicial, intermedia o final) en la que se encuentran los investigadores y el recurrir a colegas cuando necesitan información; es decir, que recurren a los colegas independientemente de la etapa en que se encuentre su investigación.

Quizá este tipo de investigadores no recurren a colegas cuando necesitan información debido, posiblemente, a que una de sus características es no tener contacto con sus colegas.

12 Sprinthall, Richard C. Basic statistical analysis. -4th ed. - Boston : Allyn and Bacon, 1994. - p. 313.. Se utilizó una medida de asociación, en este casi Chi-cuadrada, cuya formula es : $\mathrm{X}^{2}=\sum(\mathrm{fo}-\mathrm{fe})^{2} / \mathrm{fe}$

13 Rojas, Op Cit, p. 236-238. Se utilizo el Coeficiente de Pearson como medida de asciación o relación. Cuya formula es: $\mathrm{C}=\sqrt{\mathrm{X}^{2} / \mathrm{X}^{2}}+\mathrm{N}$

14 Ilidem p. 231.

La escala de valoración del coeficiente de Pearson corresponde a la siguiente tabla:

Valor del coeficiente

Menos de 25

Magnitud de la asociación o comelación

De .26 a .45

De .46 a .55

Baja

Media baja

De .56 a .75

Media

De .76 en adelante

Media alta

15 El análisis de asociación o relación entre las variables se realizó con base en la tabla mostrada en la nota anterior. 
Los investigadores que señalaron recurrir a las bibliotecas en primer lugar cuando necesitan información en las diferentes etapas de la investigación, fueron 23 sujetos de 28, 79\%, para lafinal; 16 sujetos, de 23, 70\%, para la inicial, y 41 sujetos de 71, 58 $\%$, para la intermedia. (véase figura 7). Calculando las medidas de asociación se obtuvo: $\left(\mathrm{X}^{2}\right)=4.465$ y $\mathrm{C}=.0350$.

No existe asociación entre la etapa de investigación y la utilización de la biblioteca. Los investigadores recurren a la biblioteca sin importar la etapa de investigación en la que se encuentran.

\begin{tabular}{|l|c|c|c|}
\hline \multicolumn{4}{|c|}{ Figura 6} \\
\begin{tabular}{|} 
ETAPA DE INVESTIGACIÓN EN LA QUE SE ENCONTRABAN LOS INVESTIGADORES, QUE \\
SENEALARON RECURRIR A LOS COLEGAS, EN PRIMER LUGAR, CUANDO NECESITAN \\
INFORMACIÓN
\end{tabular} \\
\hline $\begin{array}{c}\text { ETAPA DE } \\
\text { INVESTIGACIÓN }\end{array}$ & $\begin{array}{c}\text { NÚMERO DE } \\
\text { INVESTIGAD ORES }\end{array}$ & $\begin{array}{c}\text { INVESTIGAD ORES QUE } \\
\text { SENALARON RECURRIR A } \\
\text { LOS COLEGAS EN } \\
\text { PRIMER LUGAR CUAND O } \\
\text { NECESITAN } \\
\text { INFORMACION }\end{array}$ & $\%$ \\
\hline INICIAL & 23 & 1 & 4 \\
\hline INTERMEDIA & 71 & 16 & 23 \\
\hline FINAL & 29 & 1 & 3 \\
\hline
\end{tabular}

Figura 7

ETAPA DE INVESTIGACIÓN EN LA QUE SE ENCONTRABAN LOS INVESTIGADORES, QUE SEÑALARON RECURRIR A LAS BIBLIOTECAS, EN PRIMER LUGAR, CUANDO NECESITAN INFORMACIÓN

\begin{tabular}{|l|c|c|c|}
\hline \multicolumn{1}{|c|}{ ETAPA DE } & $\begin{array}{c}\text { NÚMERO DE } \\
\text { INVESTIGACIÓN }\end{array}$ & $\begin{array}{c}\text { INVESTIGADORES, } \\
\text { QUE SENALARON } \\
\text { RECURRIR A LA } \\
\text { BIBLIOTECAS, EN } \\
\text { PRIMER LUGAR, } \\
\text { CUANDO NECESITAN } \\
\text { INFO RMACIÓN }\end{array}$ & $\%$ \\
\hline INICIAL & 23 & 16 & 70 \\
\hline INTERMEDIA & 71 & 41 & 58 \\
\hline FINAL & 29 & 23 & 79 \\
\hline
\end{tabular}


Los investigadores que dijeron que recurrían a monografías en primer lugar cuando necesitaban información en las diferentes etapas de la investigación, fueron 44 sujetos de 71,62\%, para la intermedia; 16 sujetos de 29, $55 \%$, para la final, y 10 sujetos de 23, $43 \%$, para la inicial. (véase figura 8). Calculando las medidas de asociación se obtuvo: $\left(\mathrm{X}^{2}\right)=5.365$ y C $=.04171$.

No existeasociación entre la etapa de investigación y el uso de monografías. Losinvestigadores usan las monografías sin que importe la etapa de su investigación.

Los investigadores que afirmaron que consultaban las revistas en primer lugar cuando necesitaban información en las diferentes etapas dela investigación ascendieron a 10 sujetos de $23,43 \%$, para lainicial ; 17 sujetos de $71,24 \%$, paralaintermedia, y 7 sujetos de 29, $24 \%$, para la final. (véasefigura9). Calculando las medidas de asociación se obtuvo: $\left(\mathrm{X}^{2}\right)=3.547$ y $\mathrm{C}=.0280$.

No existe asociación entre la etapa de investigación y la utilización de las revistas. Los investigadores usan las revistas sin que importe la etapa de investigación en la que se encuentren.

Los investigadores que afirmaron recurrir a los colegas en primer lugar cuando necesitaban información según el tipo de investigación, corresponden a 11 sujetos de $72,15 \%$, para la básica, y a 7 sujetos de $51,14 \%$, para la aplicada. (véasefigura 10). Calculando las medidas de asociación se obtuvo: $\left(\mathrm{X}^{2}\right)=.0576$ y $\mathrm{C}=.0216$.

La asociación entre el tipo de investigación (básica y aplicada) y el recurrir a colegas cuando necesitan información no existe. Los investigadores recurren a colegas sin importar el tipo de investigación que realizan.

\begin{tabular}{|c|c|c|c|}
\hline \multicolumn{4}{|c|}{$\begin{array}{l}\text { Figura } 8 \\
\text { ETAPA DE INVESTIGACIÓN EN LA QUE SE ENCONTRABAN LOS INVESTIGADORES, QUE } \\
\text { SEÑALARON UTILIZAR LAS MONOGRAFÍAS, EN PRIMER LUGAR, CUANDO NECESITAN } \\
\text { INFORMACION }\end{array}$} \\
\hline $\begin{array}{l}\text { ETAPA DE } \\
\text { INVESTIGACIÓN }\end{array}$ & $\begin{array}{l}\text { NÚMERO DE } \\
\text { INVESTIGAD ORES }\end{array}$ & $\begin{array}{c}\text { INVESTIGAD ORES QUE } \\
\text { SEÑALARON UTILIZAR } \\
\text { LAS MONOGRAFÍAS EN } \\
\text { PRIMER LUGAR, } \\
\text { CUANDO NECESITAN } \\
\text { INFORMACIÓN }\end{array}$ & $\%$ \\
\hline INICIAL & 23 & 10 & 43 \\
\hline INTERMEDIA & 71 & 44 & 62 \\
\hline FINAL & 29 & 16 & 55 \\
\hline
\end{tabular}


El comportamiento en la búsqueda de información de los investigadores del... 27

\begin{tabular}{|c|c|c|c|}
\hline \multicolumn{4}{|c|}{$\begin{array}{c}\text { Figura } 9 \\
\text { ETAPA DE INVESTIGACIÓN EN LA QUE SE ENCONTRABAN LOS INVESTIGADORES, QUE } \\
\text { SEÑALARON UTILIZAR LAS REVISTAS, EN PRIMER LUGAR, CUANDO NECESITAN } \\
\text { INFORMACIÓN }\end{array}$} \\
\hline $\begin{array}{c}\text { ETAPA DE } \\
\text { INVESTIGACIÓN }\end{array}$ & $\begin{array}{l}\text { NÚMERO DE } \\
\text { INVESTIGAD ORES }\end{array}$ & $\begin{array}{l}\text { INVESTIGAD ORES QUE } \\
\text { SEÑALARON UTILIZAR } \\
\text { LAS REVISTAS EN } \\
\text { PRIMER LUGAR } \\
\text { CUANDO NECESITAN } \\
\text { INFORMACIÓN }\end{array}$ & $\%$ \\
\hline INICIAL & 23 & 10 & 43 \\
\hline INTERMEDIA & 71 & 17 & 24 \\
\hline FINAL & 29 & 7 & 24 \\
\hline
\end{tabular}

\begin{tabular}{|c|c|c|c|}
\hline \multicolumn{5}{|c|}{ Figura 10} \\
\begin{tabular}{|} 
TIPO DE INVESTIGACIÓN QUE ESTABAN REALIZANDO LOS INVESTIGADORES, QUE \\
SENALARON RECURRIR A LOS COLEGAS, CUANDO NECESITAN INFORMACIÓN
\end{tabular} \\
\hline $\begin{array}{c}\text { ETAPA DE } \\
\text { INVESTIGACIÓN }\end{array}$ & $\begin{array}{c}\text { NÚMERO DE } \\
\text { INVESTIGAD ORES }\end{array}$ & $\begin{array}{c}\text { INVESTIGADORES QUE } \\
\text { SEÑALARON RECURRIR A } \\
\text { COLEGASEN PRIMER LUGAR } \\
\text { CUANDO NECESITAN } \\
\text { INFORMACIÓ N }\end{array}$ & $\%$ \\
\hline BÁSICA & 72 & 11 & 15 \\
\hline APLICADA & 51 & 7 & 14 \\
\hline
\end{tabular}

Los investigadores que recurren a las bibliotecas en primer lugar cuando necesitan información según el tipo de investigación, fue de 48 sujetos de 72, 67 \%, para la básica, y de 32 sujetos de 51, $63 \%$, para la aplicada. (véase figura 11). Calculando las medidas de asociación se obtuvo: $\left(\mathrm{X}^{2}\right)=.2019$ y C $=.0405$.

No existe asociación entre el tipo de investigación y el recurrir a las bibliotecas. Los investigadores acuden a la biblioteca sin importar el tipo de investigación que están desarrollando.

Los investigadores que recurrían a las monografías en primer lugar cuando necesitaban información según el tipo de investigación, corresponden a 30 sujetos de 51, $59 \%$, para la aplicada, y 40 sujetos de 72, $56 \%$, para la básica. (vésefigura 12 ). Calculando las medidas de asociación se obtuvo: $\left(\mathrm{X}^{2}\right)=1.3000$ y $\mathrm{C}=.0325$.

No existe asociación entre el tipo de investigación y el uso de monografías. Los investigadores usan las monografías sin importar qué tipo de investigación se encuentren desarrollando. 
Figura 11

TIPO DE INVESTIGACIÓN QUE ESTABAN REALIZANDO LOS INVESTIGADORES, QUE SEÑALARON RECURRIR A LAS BIBLIOTECAS, CUANDO NECESITAN INFORMACIÓN

\begin{tabular}{|l|c|c|c|}
\hline $\begin{array}{c}\text { ETAPA DE } \\
\text { INVESTIGACIÓN }\end{array}$ & $\begin{array}{c}\text { NÚMERO DE } \\
\text { INVESTIGAD ORES }\end{array}$ & $\begin{array}{c}\text { INVESTIGADORES QUE } \\
\text { SENALARON UTILIZAR A LA } \\
\text { BIBLIOTECA EN PRIMER } \\
\text { LUGAR CUAND O NECESITAN } \\
\text { INFORMACIÓN }\end{array}$ & $\%$ \\
\hline BÁSICA & 72 & 48 & 67 \\
\hline APLICADA & 51 & 32 & 63 \\
\hline
\end{tabular}

\begin{tabular}{|l|c|c|c|}
\hline \multicolumn{5}{|c|}{ Figura 12 } \\
\multicolumn{2}{|c|}{$\begin{array}{c}\text { TIPO DE INVESTIGACIÓN QUE ESTABAN REALIZANDO LOS INVESTIGADORES, QUE } \\
\text { SEÑALARON UTILIZAR COMO FUENTE LAS MONOGRAFÍAS, CUANDO NECESITAN } \\
\text { INFORMACIÓN }\end{array}$} \\
\hline $\begin{array}{c}\text { ETAPA DE } \\
\text { INVESTIGACIÓN }\end{array}$ & $\begin{array}{r}\text { NUMERO DE } \\
\text { INVESTIGAD ORES }\end{array}$ & $\begin{array}{c}\text { INVESTIGAD ORES QUE } \\
\text { SENALARON UTILIZAR LAS } \\
\text { MONOGRAFÍAS EN PRIMER } \\
\text { LUGAR CUANDO NECESITAN } \\
\text { INFORMACIÓN }\end{array}$ & $\%$ \\
\hline BÁSICA & 72 & 40 & 56 \\
\hline APLICADA & 51 & 30 & 59 \\
\hline
\end{tabular}

Los investigadores que utilizan las revistas en primer lugar cuando necesitan información según el tipo de investigación corresponden a 22 sujetos de 72, 31 \%, para la básica, y a 12 sujetos de 51, 24\%, para la aplicada. (vésefigra 13). Calculando las medidas de asociación se obtuvo: $\left(\mathrm{X}^{2}\right)=7.368$ y $\mathrm{C}=.0722$.

\begin{tabular}{|l|c|c|c|}
\hline \multicolumn{5}{|c|}{ Figura 13 } \\
\multicolumn{5}{|c|}{$\begin{array}{l}\text { TIPO DE INVESTIGACIÓN QUE ESTABAN REALIZANDO LOS INVESTIGADORES, QUE } \\
\text { SENALARON UTILIZAR COMO FUENTE LAS REVISTAS, CUANDO NECESITAN } \\
\text { INFORMACIÓN }\end{array}$} \\
\hline $\begin{array}{c}\text { ETAPA DE } \\
\text { INVESTIGACIÓN }\end{array}$ & $\begin{array}{c}\text { NÚMERO DE } \\
\text { INVESTIGAD ORES }\end{array}$ & $\begin{array}{c}\text { INVESTIGAD ORES QUE } \\
\text { SENALARON UTILIZAR LAS } \\
\text { REVISTAS EN PRIMER LUGAR } \\
\text { CUANDO NECESITAN } \\
\text { INFORMACIÓN }\end{array}$ & $\%$ \\
\hline BÁSICA & 72 & 22 & 31 \\
\hline APLICADA & 51 & 12 & 24 \\
\hline
\end{tabular}


No existe asociación entre el tipo de investigación y el uso de revistas. Los investigadores usan las revistas sin importar el tipo de investigación que se encuentren desarrollando.

Los investigadores que dijeron recurrir a colegas en primer lugar cuando necesitan información según su categoría sumaron 13 sujetos de 50, 26\%, para los asociados, y 5 sujetos de 73, 7\%, para los titulares. (véesefigura14). Calculando las medidas deasociación se obtuvo: $\left(\mathrm{X}^{2}\right)=8.712$ y C $=.2572$.

La categoría de los investigadores (asociado y titular) tiene una relación 0 asociación baja con el hecho de recurrir alos colegas cuando necesitan información; es decir que la categoría de los investigadores tiene relación con el comportamiento de recurrir (o dejar de hacerlo) a colegas cuando necesitan información.

Los investigadores que señalaron recurrir a la biblioteca en primer lugar cuando necesitaban información según su categoría, corresponden a 37 sujetos de 73, 91 \%, para los titulares y a 43 de 50, $86 \%$, para los asociados. (véasefigura 15).

Calculando las medidas de asociación se obtuvo: $\left(\mathrm{X}^{2}\right)=16.2764$ y $\mathrm{C}=.3419$. La categoría de los investigadores tiene una relación o asociación media baja con la utilización del recurso biblioteca cuando necesitan información, es decir que la categoría que tienen los investigadores tiene relación con el recurir (o dejar de hacerlo) a la biblioteca.

\begin{tabular}{|l|c|c|c|}
\hline \multicolumn{4}{|c|}{ Figura 14 } \\
\multicolumn{1}{|c|}{ CATEGORÍA DE LOS INVESTIGADORES, QUE SEÑALARON RECURRIR A COLEGAS, } \\
CUANDO NECESITAN INFORMACIÓN
\end{tabular}

Figura 15

CATEGORÍA DE LOS INVESTIGADORES, QUE SEÑALARON RECURRIR A LA BIBLIOTECA, EN PRIMER LUGAR, CUANDO NECESITAN INFORMACIÓN

\begin{tabular}{|l|c|c|c|}
\hline \multicolumn{1}{|c|}{ CATEGORÍA } & $\begin{array}{c}\text { NÚMERO DE } \\
\text { INVESTIGAD ORES }\end{array}$ & $\begin{array}{c}\text { INVESTIGADORES QUE } \\
\text { SEÑALARON RECURRIR A LA } \\
\text { BIBLIOTECA EN PRIMER } \\
\text { LUGAR CUAND O NECESITAN } \\
\text { INFO RMACIÓN }\end{array}$ & $\%$ \\
\hline ASO CIAD O & 50 & 43 & 86 \\
\hline TITULAR & 73 & 37 & 91 \\
\hline
\end{tabular}


Los investigadores que afirmaron utilizar las monografías en primer lugar cuando necesitan información según su categoría corresponden a 41 sujetos de 50 , $82 \%$, para los asociados y a 29 sujetos de 73, $40 \%$, para los titulares. (véasefigura 16). Calculando las medidas de asociación se obtuvo: $\left(\mathrm{X}^{2}\right)=21.6252$ y C $=.3867$.

Existe una relación media baja entre la categoría de los investigadores y el uso de monografías ; es decir que la categoría que tienen los investigadores tiene relación con el comportamiento de usar (o dejar de usar) las monografías.

Los investigadores que afirmaron recurrir a las revistas en primer lugar cuando necesitan información según su categoría corresponden a 22 sujetos de 50, 44 \%, para los asociados y a 12 sujetos de 73, $16 \%$, para los titulares. (véase figura 17). Calculando las medidas de asociación se obtuvo: $\left(\mathrm{X}^{2}\right)=11.2704$ y $\mathrm{C}=.2800$.

Existe una relación o asociación media baja entre la categońa de los investigadores yel uso de revistas; es decir quela categoría que tienen los investigadores tiene relación con el comportamiento de usar (o dejar de usar) las revistas.

\begin{tabular}{|l|c|c|c|}
\hline \multicolumn{4}{|c|}{ Figura 16 } \\
\multicolumn{1}{|c|}{$\begin{array}{c}\text { CATEGORÍA DE LOS INVESTIGADORES, QUE SEÑALARON RECURRIR A LAS } \\
\text { MONOGRAFÍA, EN PRIMER LUGAR, CUANDO NECESITAN INFORMACIÓN }\end{array}$} \\
\hline CATEG ORÍA & $\begin{array}{c}\text { NÚMERO DE } \\
\text { INVESTIGAD ORES }\end{array}$ & $\begin{array}{c}\text { INVESTIGAD ORES QUE } \\
\text { SEÑALARON UTILIZAR LAS } \\
\text { MONOGRAFÍAS EN PRIMER } \\
\text { LUGAR CUAND O NECESITAN } \\
\text { INFORMACIÓN }\end{array}$ & $\%$ \\
\hline ASOCIADO & 50 & 41 & 82 \\
\hline TITULAR & 73 & 29 & 40 \\
\hline
\end{tabular}

Figura 17

CATEGORÍA DE LOS INVESTIGADORES, QUE SEÑALARON UTILIZAR LAS REVISTAS, EN PRIMER LUGAR, CUANDO NECESITAN INFORMACIÓN

\begin{tabular}{|l|c|c|c|}
\hline \multicolumn{1}{|c|}{ CATEGORÍA } & $\begin{array}{c}\text { NÚMERO DE } \\
\text { INVESTIGADORES }\end{array}$ & $\begin{array}{c}\text { INVESTIGAD ORES QUE } \\
\text { SEÑALARON UTILIZAR LAS } \\
\text { REVISTAS EN PRIMER LUGAR } \\
\text { CUANDO NECESITAN } \\
\text { INFORMACIÓN }\end{array}$ & $\%$ \\
\hline ASOCIADO & 50 & 22 & 44 \\
\hline TITULAR & 73 & 12 & 16 \\
\hline
\end{tabular}

\section{DISCUSIÓN}

La respuesta del Subsistema de investigadores cubrió más del mínimo de cuestionarios que se esperaban de forma estratificada y seleccionada al azar, por lo 
que podemos decir que la muestra es representativa y que, por tanto, se podrían hacer extrapolaciones respecto dela población total de estetipo de investigadores.

Si bien en otros países se han realizado algunos estudios sobre el comportamiento de búsqueda de información de los humanistas y los científicos sociales, en el nuestro esto no había sido posible, por lo que era importante tratar de responder estapreguntapor lo que se refiere a los investigadores del área de humanidades y ciencias sociales de la UNAM. Y la respuesta, según los resultados de esta investigación, concuerda con algunos de los resultados obtenidos en el extranjero. El comportamiento de búsqueda deinformación de nuestros investigadores en el áreade humanidades y ciencias sociales, es similar al de investigadores de las mismas áreas en otros países

Los estudios hechos por Stone, Fulton, Stieg, Kumar, Feliciano y Salter con relación a la búsqueda de información en diversas fuentes cuando los investigadores necesitan información, concluyen que el libro predomina sobre la revista, y que ésta ocupa un lugar secundario.

Para los investigadores del Subsistema de Investigación en Humanidades de la UNAM la fuente principal de información también son las monografías, pues éstas ocupan el primer lugar, en tanto que las revistas están en un lugar secundario. Tales resultados concuerdan con los obtenidos por los autores mencionados.

Pero también existen investigadores en la UNAM que utilizan como fuente obras de arte, pinturas murales, edificios, etcétera, lo cual concuerda con lo hallado por otros estudios sobre disciplinas más específicas como arte o diseño (como los realizados por $\mathrm{D}$ ay) o de historia (como los realizados por Stieg y Case). Se puede asegurar que todo depende del tema de investigación particular que esté desarrollando el investigador. Y también se puede afirmar con certeza que los investigadores estudiados se inclinan más por el libro que por la revista de manera general.

En cambio los resultados de Corkill no se corresponden con lo hallado para los investigadores dela UNAM, pues aquél concluye que para los humanistas las revistas tienen la misma importancia que las monografías.

Con relación alo queafirman Heim, Agrawal y Slater de que los científicos sociales usan como fuentes los datos de archivos, como las estadísticas, las votaciones gubernamentales, los censos, etcétera, los resultados de esta investigación concuerdan con aquéllos, pues existen investigadores del Subsistema de Investigación en Humanidades de la UNAM queusan las estadísticas vitales, los resultados delos censos, los archivos gubernamentales y los resultados de las entrevistas como datos relevantes para hacer su investigación. Estos datos se basan indudablemente en las respuestas dadas principalmente por los investigadores de los institutos de investigaciones sociales, económicas, interdisciplinarias en ciencias y humanidades, y de investigaciones multidisciplinarias.

Lo anterior implica que las bibliotecas deben prestar especial atención al desarrollo de estudios sobre sus comunidades científicas, ya que con base en los resultados que se obtengan las bibliotecas podrán enfrentar la exigente satisfacción de los investigadores desarrollando sus colecciones y diseñando servicios apropiados para ellos. 
Los resultados de esta investigación llevan a concluir que las bibliotecas deben poseer en sus colecciones las fuentes apropiadas y los servicios que respondan adecuadamente al comportamiento informativo de sus comunidades; y también señalan indudablementela gran importancia quetienelaadquisición de monografías.

Con respecto a los recursos que utilizan los investigadores cuando tienen una necesidad de información, Corkill, Stone, Fulton, Stieg, Feliciano y Salter concluyen que la biblioteca es el primer recurso al que acuden los investigadores, y que la relación con colegas (es decir la poca formación de colegios invisibles) ocupa un lugar posterior. Algunos de estos autores mencionan que tal comportamiento se debe a las características de los humanistas de trabajar de forma individual.

Los investigadores de la UNAM confirman este hecho al poner en primer lugar la utilización de la biblioteca y en un lugar posterior el contacto con colegas, con lo que ratifican la poca formación de los colegios invisibles. Esto implica que trabajen principalmente de forma individual. Este comportamiento informativo pretende actualmente modificarse tratando de impulsar que los investigadores del Subsistema de Investigación en Humanidades de la UNAM, trabajen con equipos interdisciplinarios, aspecto que posiblemente se deba al cambio mundial hacia la globalización.

Las humanidades como disciplina han venido trabajando de esta forma, por lo que un proceso de cambio podría ser muy lento o posiblemente no darse, pues implicaría modificar un comportamiento que ya tiene sus características propias, como lo demuestran los diversos estudios mencionados.

Intentar un cambio en el comportamiento de estos investigadores requeriría la realización de mayores estudios y una mejor comprensión de cómo puede éste darse. Habría que averiguar bajo qué parámetros sería posible tal cambio y cómo podría éste ser apoyado ¿Sería viable el cambio mediante el uso de las tecnologías de la información y la comunicación, como el correo electrónico, que ha logrado establecer una mayor comunicación entre los científicos de las instituciones de educación a investigación más alejadas del país? Sería necesario confirmar esta pregunta y establecer la forma en que las bibliotecas podrían apoyar este propósito, antes de hablar de coadyuvar al establecimiento de contactos con colegas y, por ende, a la formación de colegios invisibles.

Se observó que la utilización de Internet como recurso informativo no es significativa, pues sólo menos del $2 \%$ de los investigadores acudió a ella, quizá por no ser lo suficientemente confiable como para tenerla como uno de sus recursos principales. La pregunta que surge es ipor qué entonces muchas bibliotecas y profesionales de la bibliotecología le dan una importancia extrema a la búsqueda de información en Internet cuando los resultados muestran que no es un recurso principal que utilicen los investigadores cuando tienen una necesidad deinformación, por lo menos los de estas comunidades científicas? Tendría que hacerse otro estudio que nos permitiera profundizar en el tema del uso de Internet como recurso informativo y en su relevancia para la investigación. 
O tro aspecto un tanto novedoso que se investigó fuela existencia de asociación o relación entre algunas variables que inciden en el comportamiento informativo de los investigadores del área de humanidades y ciencias sociales en la UNAM con respecto al uso de fuentes y recursos, por un lado, y la etapa de investigación, el tipo de investigación y la categoría de los investigadores, por el otro.

En cuanto a lo anterior, la investigación arrojó datos interesantes, ya que existe una asociación media baja entre la categoría de los investigadores y la utilización de las monografías y las revistas. Esto suscita varias preguntas: ¿La categoría (de asociado o titular) tiene relación con el uso de monografías y revistas? ¿Q uién utiliza más las revistas los asociados o los titulares o ambos? ¿Quién utiliza más las monografías, los asociados o los titulares? Resalta de nuevo la necesidad de realizar investigaciones que profundicen en estos aspectos, pues los resultados tendrían impacto en las colecciones y el diseño de servicios bibliotecarios de atención a los investigadores (asociados y titulares).

Lo mismo ocurrió con la categoría y la utilización de la biblioteca como recurso para obtener la información que necesitan estos investigadores, ya que presenta una relación media baja. Esto puede significar que la biblioteca es más utilizada por algún tipo de categoría (asociado o titular), pero habría que profundizar en el asunto antes de averiguar si son los asociados o los titulares quienes más utilizan la biblioteca, y encontrar las razones de esto. Pero hay que recordar que los titulares tienen mayor nivel y por tanto mayor grado de desarrollo académico o por lo menos estatutariamente así está establecido. Basándose en estos resultados, la biblioteca podría diseñar sus servicios para atender a una determinada categoría de investigadores y responder a su comportamiento, o bien atraerlos hacia la biblioteca sin importar su categoría.

En cambio hay una asociación baja entre la categoría de los investigadores y el recurrir a colegas cuando necesitan información. Surgen las preguntas ¿Son los investigadores titulares quienes tienden más hacia el contacto con colegas o son los asociados los que tienden más hacia el contacto con colegas?Y de ser esto así ¿cómo debe responder la biblioteca para apoyar la categoría que esté más inclinada a establecer estos contactos?

\section{CONCLUSIONES}

Las bibliotecas son un recurso primordial para apoyar las labores de investigación en Humanidades y Ciencias Sociales en la UNAM, pues los investigadores recurren principalmente a ellas para obtener la información que necesitan. Esto implica que las bibliotecas deben contar con colecciones que respondan adecuadamentea las necesidades y el comportamiento de los investigadores en humanidades y ciencias sociales. Este comportamiento, reiterado en esta investigación, confirma los estudios realizados en otros países con investigadores de las mismas áreas. 
Lo anterior no quiere decir que los contactos escasos queden descartados como parte del comportamiento informativo de estos investigadores, fenómeno que confirman otros autores que también han investigado este aspecto.

Los investigadores recurren principalmente a las monografías como fuente de información, a las que siguen las publicaciones periódicas y otros tipos de recursos como edificios, obras de arte, etcétera. Esto supone que las colecciones de las bibliotecas deben atender debidamente el comportamiento informativo de su comunidad científica respondiendo con un acceso fluido a las fuentes apropiadas y dándole prioridad a las monografías.

Hasta el momento, la utilización de Internet no tiene un lugar importante para los investigadores cuando éstos buscan información, lo cual debe ser tomado en cuentapor la propia comunidad bibliotecaria que no considera a Internet como recurso relevante. Esto puede deberse a diversos factores: poca confiabilidad de la información y falta de precisión tanto en la búsqueda como en la obtención del documento.

La categoría del investigador (asociado o titular) tiene asociación o relación con el uso de las fuentes y recursos informativos, aspecto que debe indagarse con mayor profundidad tomando en cuenta que los investigadores titulares tienen un nivel más alto que el de los asociados. Cabe plantearse las siguientes incógnitas: ¿Los asociados recurren más a las monografías que los titulares? ¿Los asociados recurren más a las revistas que los titulares? ¿Los asociados recurren más a los colegas que los titulares? 0 viceversa ¿Los titulares recurren más a las monografías que los asociados? ¿Los titulares recurren más a las revistas que los asociados? ¿Los titulares recurren más a los colegas que los asociados?.

También se puede afirmar que cuando los investigadores tienen necesidades de información, la etapa de investigación en la que se encuentran sus indagaciones no tiene relación o asociación con el uso de fuentes y la utilización de recursos.

Así también el tipo de investigación que están realizando los investigadores no tiene relación o asociación con el uso defuentes y recursos que utilizan cuando están a la búsqueda de información.

\section{RECOMENDACIONES}

Las bibliotecas que atienden a las comunidades científicas de humanidades y ciencias sociales deben ser rotundamente apoyadas a través de la asignación de locales, personal, colecciones, equipo y mobiliario adecuados para que puedan brindar servicios que satisfagan cabalmente las necesidades y el comportamiento informativo de los investigadores, puesto que son un recurso primordial para apoyar la investigación, tal como lo confirman los resultados de este trabajo.

Así, estudiar el comportamiento de búsqueda de información de la comunidad científica es importante, pero su oportuna satisfacción sólo se dará a través del diseño adecuado de los servicios bibliotecarios y de información. 
En nuestro medio nacional es de vital importancia que los servicios de información apunten alaplena satisfacción de las necesidades del usuario. Pero para que las unidades de información alcancen este propósito será necesario antes estudiar e identificar el comportamiento informativo de la comunidad científica a la que se va a atender.

Para nuestros países en vías de desarrollo es importante empezar realizar estudios periódicos que permitan identificar las necesidades de información y el comportamiento informativo de los usuarios, para que las unidades de información les respondan a sus comunidades científicas con pleno conocimiento completo de ellas y lo más adecuadamente posible.

\section{BIBLIOGRAFÍA}

AGRAWAL, S. P. y M. Lal " Information needs of social scientists". En: Intema tional libraryreview No. 19, 1987. p. 287-299.

BARBERENA, Elsa. Las necesidades de información en el área científica. [México] : [s.l.], 1982. 20 p.

BETTIO L, Eugenia Maranhao "Necessidades de informacao : uma revisao". - En: Reista da biblideconomia da Brasilia Vol. 18, no. 1, jan.jun. 1990. p. 59-69

CALVA GONZÁLEZ, Juan José. "Una aproximación a lo que son las necesidades de información." En: Invesigacónbiblicteedójica: archivonmá, bibideedoǵa einformacón Vol. 5, no. 11, jul-dic. 1991. p. 24-32

- - "Las necesidades deinformación de la comunidad académica como base en el desarrollo de colecciones". En: Pinmer Seninanio Intemadional sdreDesandlode Cdeciones México : UNAM, Centro Universitario de Investigaciones Bibliotecológicas, 1998.

- - "Las necesidades de información de las comunidades científicas dentro del Progra ma de Formación de Recursos Humanos en Servicios Bibliotecarios y de Informa ción para la integración de la Red de Bibliotecas del Subsistema de Humanidades y

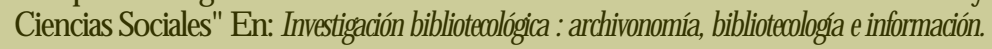
Vol. 10, no. 20, enejun. 1996. p. 33-35

- - "Las necesidades de información de los usuarios en la planeación bibliotecaria". En: Biblictecaunivesitania. boleíninfomativodelaDireccón General deBiblicteas Vol. 6, no. 1, ene.mar. 1991. p. 25-30

- - "Las necesidades de información del usuario en la automatización de unidades de información". En: Bididtecaunivesitaria bodeíninformativodelaDireción General deBiblideeras Nueva Época, Vol. 1, no.1, ene-jun. 1998. - p. 15-20.

- - "Las necesidades de información : la importancia de su estudio. En: Biblio teca univesitaria: boleíninfomativodela DireciónGeneral deBiblictecas Vol. 9, no. 3, jul-sep. 1994. p. 33-38. 
- - Las necesidades de información: su naturaleza, manifestación y detección. México :J.J.Calva G onzález, 1998. Tesis (Maestría en Bibliotecología) UNAM. Facultad de Filosofía y Letras, 1998.

- - "Surgimiento y manifestación de las necesidades de información de los investigadores". - En: Investigadónbiblidtedoógica: ardivonomáa, biblictedogóa einformacón Vol. 9, no. 19, jul-dic. 1995. p. $17-29$

CASE, D. O. "The collection and use of information by some american historians : a study of motives and methods". En: LibraryQuately. Vol. 61, no. 1. 1991. p. 61-82.

CIRIG LIANO, G ustavo F.J. Lacondudainfomativaenunivesitariosargentinos Buenos Aires : Universidad de Buenos Aires. Facultad de Filosofía y Letras, Centro de Investigaciones Bibliotecológicas, 1971.

CORKILL, C. y M. Mann. Infomationneedsinthehumanities: twopos tal survey. Sheffield : University of Sheffield, 1978.

D AY, J. y E. MacD owell. "Information needs and use of art and design student". En: Education libraries bullein Vol. 28, p.1, spring 1985. p. 31-41.

Feliciano, M. S. "Access to law : information needs of researchs in law and the public". En: Theuse of infomation in the dangingworld Norht Holland : Elsevier, 1984. p. 197-208.

FESTING ER, L. Losmátodbsdeinvestigaaónenlasaienciassoiales Buenos Aires : Paidós, 1979.

FRENCH, Beberlee A. "User needs and library services" .En: Librarytrends Vol. 38, no. 3 winter, 1990. p. 415-441.

FULTON, C. "Humanists as information users : a review of the literature". - En:A ustralianacademicandresearchlibraries V ol. 22, no. 3. 1991, p. 188-197.

HEIM, K. M. "Social scientific information needs for numerical data: the evolution of international data archive infraestructure". En: Cdlectionmanagement. V ol 9, no. 1, spring 1987. p. 1-54.

KUMAR. Girja. "Use of information in social science: a conceptual framworks". En: Theuse of information in the dhanging world Norht Holland : Elsevier, 1984. p. 241-251.

MAGALONI DE BUSTAMANTE, Ana María. Una alternativa para evaluar y diseñar servicios especializados de información documental. México: UNAM: Centro Universitario de Investigaciones Bibliotecológicas, 1984.

"Modificaciones al Estatuto G eneral de la UNAM aprobadas por el Consejo Universitario en su sesión del 28 de abril de 1995". En: Gacta UNAM. No. 2925, 22 may. 1995. p. 24-25 
MORALESCAMPOS, Estela. "Bibliotecología e información" En: Bdéíndela AsociacónA Andaluza deBiblidecarios Año, 5, no. 15, 1989. p. 13-21

O 'D O NNEL, Pacho. Teenayténicadelapsicterapiagupal. Buenos Aires: Amorrortu, 1974.

PIMRUMPAI PREMSMIT. "Information needs of academic medical scentists at Chulalongkorn University". En: Bullein of medical libraryAssociation Vol. 74, no. 4, 1990. p. 383-387.

ROJAS SO RIANO, Raúl. Guíapararealizarinvestigadionssociales México : UNAM, 1982

ROMAN HAZA, María Trinidad. Compatamientoinfomatiodelosetudantes delaliceniahuradelascareasdequímicayfíisa México : UNAM. Centro Universitario de Investigaciones Bibliotecológicas, 1986.

SANTOS ROSAS, Antonia y Juan José Calva G onzález. Lasneecidades deinformacóndd usuariodelabiblictecadelaDireciónGeneal deContrd SanitariodeBie nes y Servicios [México : SSA, D irección General de Control Sanitario de Bienes y Servicios, 1995].

SLATER, M. Infomationneedsfosocial scientists: astudybydesk rearchandinteriew [London] : Brotish Library Research, 1989.

- - "Information needs and communication problems of social scientists The United Kingdom situation". En: Intemational jaumal ofinfomationandlibraryrearch Vol. 1, no. 2, 1989. p. 131-144.

- - "Social scientists' information needs in the 1980s". En: Jaumal ofdbamentation Vol. 44, no. 3, sep. 1988. p. 226-237.

SPRINTHALL, Richard C. Basicstatistical analysis Boston : Allyn and Bacon, c1994. - p.312-331.

STIEG, M F. "The information of needs of historians" . En: Collegeandresarch libraries November 1981. p. 549-561.

STONE, S. E dit. "CRUS humanities research programme”. En: Humanitiesinfomation rearch procedings of a seminar Sheffield 1980.

UNIVERSID AD NACIO NAL AUTÓ NOMA DE MÉXICO. Agendaestadística1993. México : UNAM. Dirección G eneral de Estadística y Sistemas de Información Institucionales, 1993.

UNIVERSIDAD NACIONAL AUTÓNOMA DE MÉXICO. [LEGISLACIÓN] Leejsacoón. México : UNAM, Oficina del Abogado General, 1987 


\section{A NEXO I}

UNIVERSIDAD NACIONAL AUTÓNOMA DE MÉXICO CENTRO UNIVERSITARIO DE INVESTIGACIONES BIBLIOTECOLÓGICAS ENCUESTA SOBRE LAS NECESIDADES DE INFORMACIÓN DE LOS INVESTIGADORES

La encuesta es ANÓNIMA y los datos que usted proporcione tienen gran importanciay podrían ser utilizados para desarrollar los servicios bibliotecariosy deinformación.

Es preciso enfatizar que usted fue seleccionado al azar como parte de una muestra de investigadores, y que la validez del estudio descansa en que nos proporcione verzamente los datos que le solicitamos en la presente encuesta. INSTRUCCIONES GENERALES

A) Registre en la HOJA DE RESPUESTAS el o los dígitos correspondientes a la(s) alternativa(s) seleccionada(s).

B) El tiempo estimado para responder esta encuesta es de 5 minutos ya que las preguntas son muy sencillas.

C) Rogamos a usted escribir con números claros y con letra de imprenta.

D ) Es imprescindible que responda todas las preguntas

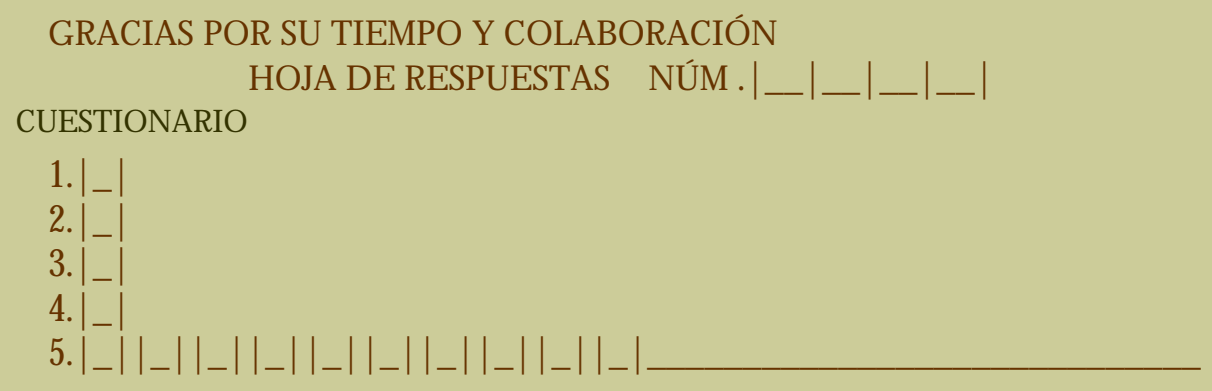

OTRO RECURSO

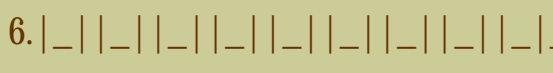

OTRA FUENTE

CUESTIONARIO

I. DATOS GENERALES

MARQUE SÓ LO UNA RESPUESTA

1. ¿A qué subsistema pertence?

1. Investigación humanística

2. Investigación científica

2.- ¿En qué etapa se encuentra su investigación?

1. Inicial

2. Intermedia

3. Final 
3.- ¿Q ué tipo de investigación está realizando?

1. Básica

2. Aplicada

4.- ¿Cuál es su categoría?

1. Investigador A sociado

2. Investigador Titular

\section{RECURSO S Y FUENTES Q UE UTILIZA}

Señale su respuesta de manera jerárquica, anotando los números en orden de prioridad según la importancia en que utilice los recursos y las fuentes.

Puede anotar el número de opciones que considere necesarias.

5.- ¿Q ué recursos utiliza cuando necesita información?

1. Colegas.

2. Bibliotecas, hemerotecas, centros de documentación, centros de información, etcétera.

3. Colección documental propia.

4. Colecciones documentales particulares de colegas.

5. Experiencia personal.

6. Expertos en el área.

7. Congresos, conferencias, seminarios, encuentros.

8. Bases de datos bibliográficas (ej. medline, psyclit).

9. Bancos de datos especiales (ej. bancos de genes, bancos de datos numéricos, etcétera). 10 Otro, especifique.

6.- ¿Q ué fuentes utiliza cuando necesita información?

1. Monografías (libros, tesis, documentos, etcétera).

2. Publicaciones periódicas (revistas, diarios, anuarios, etcétera).

3. Publicaciones oficiales (informes de organismos nacionales y extranjeros, etcétera).

4. O bras de consulta (enciclopedias, diccionarios, manuales, etcétera).

5. Fuentes referenciales (índices, abstracs, bibliografías, etcétera).

6. Material audiovisual(casetes, videos, etcétera).

7. D ocumentos técnicos (patentes, partituras, planos, mapas, etcétera).

8. Fuentes de datos numéricos (indicadores, estadísticas, etcétera).

9. O tros, especifique. 
40 Investigacón Biblicteedógica V. 13 No. 27 julio/ diciembre de 1999

\begin{tabular}{|c|c|}
\hline \multicolumn{2}{|l|}{ ANEXO II } \\
\hline \multicolumn{2}{|c|}{$\begin{array}{l}\text { LOS INVESTIGADORES QUE CUMPLEN LAS CARACTERÍSTICAS SOLICITADAS PARA } \\
\text { ESTE ESTUDIO SE ENCUENTRAN DISTRIBUIDOS DE LA SIGUIENTE MANERA }\end{array}$} \\
\hline CENTRO O INSTITUTO & $\begin{array}{l}\text { NÚMERO DE } \\
\text { INVESTIGADORES }\end{array}$ \\
\hline $\begin{array}{l}\text { CENTRO COORDINADOR Y DIFUSOR DE ESTUDIOS } \\
\text { LATINOAMERICANOS }\end{array}$ & 11 \\
\hline CENTRO DE ESTUDIOS SOBRE LA UNIVERSIDAD & 33 \\
\hline $\begin{array}{l}\text { CENTRO DE INVESTIGACIÓN INTERDICIPLINARIA EN } \\
\text { CIENCIAS Y HUMANIDADES }\end{array}$ & 11 \\
\hline $\begin{array}{l}\text { CENTRO DE INVESTIGACIONES SOBRE AMÉRICA } \\
\text { DEL NORTE }\end{array}$ & 12 \\
\hline $\begin{array}{l}\text { CENTRO REGIONAL DE INVESTIGACIONES } \\
\text { MULTID ISCIPLINARIAS DE LA UNAM }\end{array}$ & 20 \\
\hline $\begin{array}{l}\text { CENTRO UNIVERSITARIO DE INVESTIGACIONES } \\
\text { BIBLIOTECOLÓGICAS }\end{array}$ & 13 \\
\hline INSSTITUTO DE INVESTIGACIONES ANTROPOLÓGICAS & 40 \\
\hline INSTITUTO DE INVESTIGACIONES BIBLIOGRÁFICAS & 18 \\
\hline INSTITUTO DE INVESTIGACIONESECONÓMICAS & 55 \\
\hline INSTITUTO DE INVESTIGACIONES ESTÉTICAS & 30 \\
\hline INSTITUTO DE INVESTIGACIONES FILOSÓFICAS & 22 \\
\hline INSTITUTO DE INVESTIGACIONES HISTÓRICAS & 27 \\
\hline INSTITUTO DE INVESTIGACIONES JURÍDICAS & 46 \\
\hline INSTITUTO DE INVESTIGACIONES SOCIALES & 53 \\
\hline TOTAL & 391 \\
\hline INSTITUTO DE INVESTIGACIONES FILOLÓGICAS & $\begin{array}{l}\text { NO ENVIÓ } \\
\text { DATOS }\end{array}$ \\
\hline
\end{tabular}
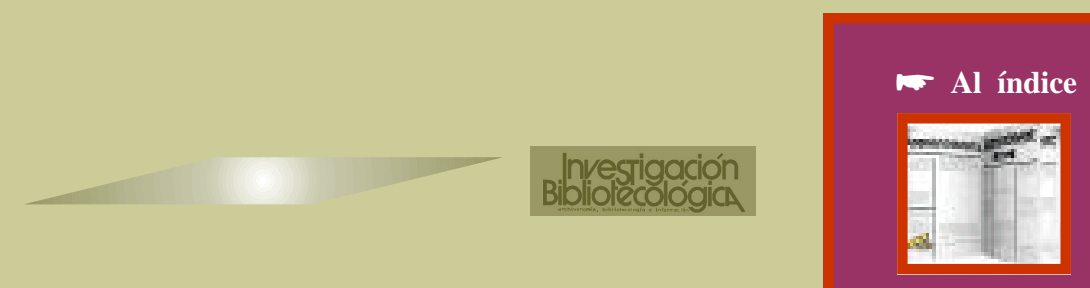

w siguiente artículo 